\title{
El Museo Matachín, 32 años de trabajo comunitario
}

\author{
Alejandro Hartmann Matos \\ Historiador de la ciudad \\ Director del Museo Matachin, Cuba \\ hartman@gtmo.cult.cu
}

\section{Resumen}

Este trabajo es una ponencia presentada en la décimo sexta Conferencia Internacional del Movimiento para una Nueva Museología, MINOM-ICOM ${ }^{1}$, celebrada en la ciudad de La Habana, del 6 al 11 de octubre del 2014; y es el resultado de las experiencias personales del Director del Museo de Matachín, Baracoa (Cuba), el cual ha funcionado durante 32 años de manera ininterrumpida, sumando experiencias únicas que se iniciaron cuando se inauguraron museos en todos los municipios de Cuba por la Ley 23 de la Asamblea Nacional del Poder Popular.

Desde su inicio - y a través de todos estos años - el Museo de Matachín ha sido un aporte significativo a la museografía cubana debido al arduo trabajo comunitario que, en el caso de Baracoa donde el $95 \%$ del municipio es montaña y de difícil acceso, se han visitado las escuelas más apartadas y a todos los campesinos que viven en esos intrincados lugares.

“...pero este trabajo lo hemos hecho con todo el amor del mundo, porque el museólogo con el amor, todo lo puede"

\begin{abstract}
This work is based on a report presented in the 16th International Conference of the Movement for New Museum Studies (MINOM-ICOM), celebrated in the city of Havana from the 6th to the 11th of October, 2014. It relates the personal experiences of the Director of the Museum of Matachín, Baracoa, Cuba, who has worked in the job continuously for 32 years, and who has had many unique experiences, beginning from the time museums were first opened in all parts of Cuba by order of Law 23 of the National Assembly of Popular Power.
\end{abstract}

1 Organización afiliada al Consejo Internacional de Museos, ICOM. 
Since its opening — and through the years - the Museum of Matachín has made a significant contribution to the Cuban museum system owing to the difficult community work involved and to the fact that Baraco is a region where $95 \%$ of the land is mountainous and difficult to access. The museum has been visited by students who attend the most isolated schools and by rural people who live in the most inaccessible of areas.

"But we have done this work with all the love in the world because arranging a museum with love is something everyone can do".

Cuando empezamos, emprendimos nuestro trabajo solo con los instrumentos de la sensibilidad y la intuición. Desconocíamos los términos sistema de documentación, conservación, investigación, promoción, animación cultural, programa y proyecto cultural. Estar muy ligado siempre a mis tradiciones, a las costumbres baracoanas, a sus comidas típicas que siempre he deleitado, a la longeva historia de mi Ciudad Primada, a la manera peculiar de ser del baracoano, a esas innumerables leyendas que oí desde pequeño a mis antecesores, fue impulso del corazón para la responsabilidad que iba a enfrentar.

Al comenzar a dirigir el museo tuve una posibilidad: profundizar en las características y peculiaridades de nuestro territorio. Así pude entender con más claridad y precisión la idiosincrasia del baracoano, su ética, sus costumbres, sus hábitos, el sentido de autopertenencia de los distintos asentamientos poblacionales. El contacto con un sinnúmero de informantes de distintas zonas de la región coadyuvó indudablemente a ampliar mis conocimientos acerca de estas: particularidades del área geográfica, sus cultivos, los intereses comunes, los lazos de parentescos; la importancia de la familia, como núcleo esencial de la sociedad en la conformación de la identidad del individuo en su contexto; los problemas colectivos que han aunado y los ha identificado, creándole un sentimiento de pertenencia al grupo. Todo aquello me explicó la cohesión que siempre ha identificado a Baracoa.

Tuve en aquellos momentos toda la ayuda del director de Cultura, hombre con intuición y sensibilidad. Gracias a su apoyo incondicional y confianza depositada en mí, pude con libertad buscar la cooperación de cuatro compañeras que laboraron conmigo de manera voluntaria en todo el proceso de investigación y búsqueda de objetos para el museo. Fue un año de labor de todos, unidos a los comités de defensa de la Revolución, a la Federación de Mujeres Cubanas, a centros de trabajo, a la Comisión de Historia del Partido y a un grupo de espontáneos hombres y mujeres que fueron pilares en la consecución de nutrirnos de diferentes colecciones para el museo.

Al inaugurarse el Museo Matachín, el 18 de octubre de 1981, nos enfrentamos a una situación dada que teníamos que transformar para llegar a los objetivos que 
nuestra institución tenía como meta. Por lo tanto, nos sumergimos en conocer la realidad en todos sus ámbitos de nuestro municipio: qué característica presentaba; cuál había sido su proceso histórico, con qué recursos naturales contábamos; qué composición poblacional la caracterizaban; qué recursos institucionales estaban contribuyendo a su transformación (organizaciones políticas y de masas, cooperativas, unidades militares, la escuela, el transporte, la electricidad, la salud pública, entre otros) y cómo eran las particularidades de las familias, núcleo esencial en la sociedad, porque a través de ella es que se van a practicar las actividades sociales elementales y a través de ella íbamos a conocer los portadores de la cultura local en la que se ha transmitido de generación en generación las tradiciones y costumbres que identifican a la comunidad. Otro elemento que tuvimos en cuenta fue el conocer los medios recreativos y el empleo del tiempo libre de sus pobladores. Con estos indicadores del diagnóstico, podíamos fundamentar que Baracoa, primera villa de Cuba, fundada el 15 de agosto de 1511, durante cuatro siglos fue preterida y olvidada. Al triunfo de la Revolución, tenía el más alto nivel de analfabetismo, depauperación socioeconómica, de desempleo y crítica situación en la salud. Esto hizo que la denominaran la Cenicienta de Oriente. La Revolución cambia su status y por doquier encontramos una escuela rural en los lugares más apartados del municipio, cooperativas de producción y servicios: se garantiza el transporte a través de caminos de montañas, se han electrificado todas las zonas del territorio y tenemos 19 hidroeléctricas en las zonas de más difícil acceso, se ha extendido la red de servicio de agua potable con un acueducto por gravedad y 20 para otras comunidades. No obstante esos beneficios sociales, en las montañas detectamos un éxodo preocupante. Como elementos homogéneos en todos los núcleos poblaciones pudimos constatar el mantenimiento de las tradiciones danzario-musicales, la artesanía popular tradicional, la literatura oral, las comidas y bebidas típicas y la reservación de las acepciones de variados signos lingüísticos.

Lo cuestionado en la formación histórico-patriótica arrojó un desconocimiento general de la historia de cada comunidad, desde las culturas aborígenes hasta los hechos más significativos acontecidos hasta la fecha. Se pudo comprobar también el poco dominio de los símbolos patrios y de los biografías de los mártires caídos. Teniendo en cuenta estos problemas, confeccionamos un proyecto cultural que comprendió tareas concretas para cada asentamiento poblacional y zonas priorizadas, pero todo esto unido a los distintos factores que tienen que ver con el desarrollo global. Porque no es posible llegar a metas en el trabajo cultural si no hay la unión de todos los recursos institucionales y humanos que hacen realidad la cultura en nuestro socialismo. Y nos referimos a las cooperativas, organizaciones políticas y de masas, instituciones culturales de la comunidad, el maestro, los delegados de la circunscripción, los campamentos del EJT (Ejército Juvenil del Trabajo), unidades militares, el médico de la familia, los instructores, los promotores, los cuentapropistas, entre otros. 
Por eso nos propusimos los siguientes objetivos:

- Fortalecer el trabajo histórico-patriótico, priorizando el de las zonas más apartadas del municipio.

- Impartir cursos de historia de la localidad en las escuelas urbanas y rurales.

- Contribuir al fortalecimiento del trabajo político-ideológico trazado en los lineamientos de nuestros congresos del Partido.

- Dar a conocer el proceso histórico de Baracoa desde las culturas aborígenes hasta los hechos más significativos de la Revolución.

- Estrechar el vínculo museo-comunidad a través de los recursos humanos e institucionales.

- Reafirmar los valores locales, contribuyendo al autoreconocimiento de cada comunidad.

- Elevar el nivel de vida de cada comunidad a través de las actividades propiciadas por la institución.

- Hacer partícipe activa a la comunidad en las acciones de la institución.

- Contribuir a la formación estética-cultural de la comunidad.

Nos propusimos, en primera instancia, como tarea ineludible, impartir un curso de historia de la localidad que recogiera todo el proceso histórico de nuestro municipio desde los indios hasta los logros más importantes del período revolucionario. Coordinamos con la escuela y en la sesión contraria a las actividades docentes; el grupo seleccionado recibe una vez a la semana, en 45 minutos, la información de un técnico de la institución. Con anterioridad hacemos un programa que dosifica el contenido y se tiene en cuenta el curso escolar para comenzarlo y concluirlo. Desde que inauguramos el museo, hasta este año, se han impartido 416 cursos de historia de la localidad a 4.992 escolares.

Al final de cada año escolar se hace un evento de investigación, donde los niños presentan una ponencia de un tema seleccionado acerca de la historia de la localidad, el medio ambiente, las tradiciones danzario-musicales, las culinarias, el patrimonio arquitectónico y uno muy importante: la vida, obra y pensamiento de nuestro apóstol José Martí. 
Aquí se involucra el maestro, el padre, el tío y el resto de la familia. El niño desarrolla habilidades y destrezas en cómo hacer una ponencia, pero lo más importante es el fortalecimiento del sentido de pertenencia que se logra en ellos. Así fomentamos el amor por su comunidad. Con los cursos apoyamos los programas de historia de Cuba y de la localidad, en $5 .^{\circ}$ y $6 .^{\circ}$ grados y en la secundaria básica. Con este concepto contribuimos a la educación estéticacultural, histórico-cultural e ideo-política como elemento trascendente en su formación integral. Hemos realizado 32 encuentros de investigación con 2.624 trabajos presentados. Algo muy significativo para lograr el éxito de estos es el apoyo de la Organización de Pioneros José Martí, la Unión de Jóvenes Comunistas y la Dirección Municipal de Cultura.

Nuestro museo siempre ha estado traspasando sus muros y se ha unido con las casas de cultura, la librería, la biblioteca, la banda municipal, la Casa de la Trova, la galería de arte, el cine, para llevar adelante, por una y otra parte, los objetivos propuestos en el municipio, porque la cultura es un sistema del que no se puede prescindir. De ahí la experiencia en las tertulias y en el espacio Tradiciones.

Sus temas están correspondidos con el proceso histórico cultural, las tradiciones danzario-musicales, las culinarias, el patrimonio arquitectónico e inmaterial y el medio ambiente de la región. Todos relacionados con las colecciones del museo. En estos años hemos involucrado a los promotores e instructores de los 15 consejos populares, para que todas las comunidades aporten a estos con su riqueza cultural e histórica.

Otra actividad priorizada es el espacio "Los niños cuentan su Historia", destinada al público infantil. Esta se destaca por ser una experiencia enriquecedora para el quehacer comunitario de la institución, que se realiza en coordinación con la UJC, OPJM, Mined, Inder, ACRC, otras instituciones culturales y los promotores culturales e instructores de arte de los distintos asentamientos poblaciones. Hace 20 años se extendió hacia las escuelas primarias del municipio, incluyendo las de enseñanza especial y los círculos infantiles. Se celebran efemérides, ya sea del ámbito nacional o de la localidad; combatientes cuentan sus experiencias: se recuerdan hechos como el desembarco de Maceo, entre otros aspectos significativos. Se inculcan en los niños sentimientos de amor hacia la historia local, sus costumbres, tradiciones y la importancia de conocerlos. Se vincula al maestro con la dirección del centro y otros factores de la comunidad con el quehacer de nuestro trabajo. Nos apoya además la casa de cultura municipal, que nos ofrece sus proyectos creados con niños, ejemplo de estos: "Sonetos del Futuro", "Campanitas Vivas", "Rayitos de Sol" y otros. Estos se presentan en la actividad, la que enriquecemos con cuentos, poesías, juegos y preguntas de participación, dibujo sobre asfalto, representación de obras teatrales y demás. En ocasiones nos acompañan especialistas del Centro de Promoción de Salud Municipal, quienes abordan temas relacionados con la higiene personal que debe tener cada niño en su escuela. 
Con perenne presencia nuestro centro es partícipe activo de todos los planes asistenciales convocados por el gobierno de la localidad, giras comunitarias, festivales y conmemoración de todas las fiestas locales y nacionales. Esto nos ha permitido una plena identificación entre las comunidades y nuestra institución. Otra experiencia vital ha sido la conexión con la Unión de Jóvenes Comunistas, el Ministerio de Educación, el Comité de Defensa de la Revolución, la Federación de Mujeres Cubanas, la CTC, la OPJM, la Anap, el Inder, la Aclifim, la Anci, la Ansoc, el Minint, el Minfar, la Uneac, la AHS, el Citma y la ONG Fundación Antonio Núñez Jiménez de la Naturaleza y el Hombre, el Mintur, la Filial de Ciencias Médicas, el Centro Universitario y la Asociación de Combatientes de la Revolución Cubana. De acuerdo con las características de cada uno, así nos hemos planificado tareas que cumplan los objetivos mutuos, como por ejemplo: en las caminatas a lugares históricos, en la preparación histórico-patriótica de los jóvenes, en la celebración de las efemérides o en el aniversario de un mártir cuyo nombre lo lleva un CDR o un centro de trabajo, entre otras actividades. Nuestra institución es sitio constante de las firmas del Código de Ética, en la entrega de la condición de Vanguardia Nacional de las empresas y centros de trabajo y en el recibimiento de personalidades políticas, culturales, científicas y deportivas que nos visitan.

También en estos años hemos tenido una línea muy bien definida en cuanto al acceso y la relación hombre-acción cultural y participación. La línea consiste en que la institución no puede prescindir de los distintos factores que hacen posible el cumplimiento de la política cultural. De ahí lo positivo que ha sido integrar a la actividad de la institución varios grupos de trabajadores, profesores, campesinos, estudiantes y profesionales. Ejemplo de esto es el Grupo de Arqueología Cacique Hatuey, hoy miembro de la Sociedad Espeleológica de Cuba, que, debido a su apoyo, nuestras salas exhiben valiosas piezas de las culturas precolombinas de la región; a través de ellos hemos localizado 56 sitios arqueológicos que conforman nuestros antecedentes históricos y hemos podido hallar la expresión plástica de su mundo, reflejado en sus pictografías y petroglifos. Esto, a su vez, nos ha permitido establecer el cuidado y conservación de estos lugares de nuestra prehistoria, como es el caso de los petroglifos de San Justo, Yara, en lo que el campesino Regino Rodríguez es el activista encargado de velar, protegerlos y controlar las visitas de las escuelas, de los cooperativistas, de los obreros y de otros visitantes.

\section{El museo móvil es otra de las experiencias}

Logradas en 32 años de labor. Esto ha trascendido decisivamente en educar y elevar el nivel histórico-estético e informativo-cultural de las comunidades. Llevar muestras de nuestras colecciones a grupos humanos apartados de la ciudad, que no tienen acceso a visitarnos, ha sido premisa obligada, dada las características que posee Baracoa en su composición demográfica, en la que el mayor porcentaje de su población es rural. El museo móvil ha llegado a la 
comunidad y ha pasado a ser, en relación biunívoca con esta, un vehículo idóneo para su formación y desarrollo de su nivel de vida. El museo móvil ha recorrido las cooperativas, las escuelas de distintos niveles, los CDR, los bloques de la FMC, los campamentos del Ejército Juvenil del Trabajo, las unidades militares los consultorios médicos de la familia, la prisión de nuestro municipio, los centros de trabajo, el Centro Universitario y la Filial de Ciencias Médicas. Con él hemos llegado a las montañas de más difícil acceso, como el Naranjo del Toa, a dos horas de navegación en cayuca (pequeña embarcación que se usa para navegar por los ríos como el Toa, Yumurí, Quiviján, etc.).

Para este trabajo mandamos a confeccionar una vitrina portátil formada por tres secciones que consisten en una estructura de plywood de 110 centímetros de largo por 80 de ancho y 15 de profundidad. En la parte superior se le agrega una pieza con el cristal, y en la parte inferior, patas plegables. Esto nos ha permitido llevarla en una guagua, en un jeep, en una cayuca, en un caballo o en un mulo. Resulta ligera y fácilmente transportable. Nosotros, con las condiciones materiales que teníamos a nuestro alcance, pudimos hacer este tipo de vitrina, por lo que somos del criterio - y la experiencia nos lo ha confirmado- de que cualquier tipo de vitrina o mueble puede jugar el mismo papel en cuanto al montaje que representa el objeto museable. Empezamos esta actividad por los poblados que por sus características sociopolíticas se les da una atención prioritaria por parte de las organizaciones de la comunidad. De ahí trazamos el plan para llevar a la práctica, desde enero de 1982 hasta la fecha, el museo móvil. De acuerdo con las zonas, hemos venido exhibiendo las piezas que juegan un papel informativo, didáctico o histórico-cultural. Esto ha propiciado que los pobladores de distintos lugares nos hayan traído valiosos materiales que, en su mayoría, han considerado sin importancia.

En varias ocasiones se nos ha presentado esta reacción por parte del pueblo. En una muestra de arqueología nos sucedió algo sorprendente y agradable. Cuando exhibimos algunas hachas petaloides, un campesino fue motivado porque él las conocía como "piedra de rayo". Nos informó que el poseía una. Nos la trajo, la exhibimos y la donó al museo. Ha sucedido también con los fragmentos de cerámica que ellos denominan "pedacitos de barros". En el cúmulo de experiencias, nos sucedió un caso muy interesante. El maestro de la escuela de Manglito, localidad a 25 kilómetros al este de la ciudad, cuando montábamos un museo móvil, nos dio para exhibir un hacha de cuello de gran tamaño, que, según los especialistas, es la más grande que se ha hallado en la historia de la arqueología cubana y del Caribe. Un tanto similar nos ha pasado con las exposiciones relacionadas con las guerras de la Independencia. Las medallas de veteranos, los machetes de los mambises, las órdenes de ascenso, etc., han producido una actitud igual en los espectadores. Han traído lo guardado por sus antecesores, conservado de generación en generación. Es norma nuestra, después de que explicamos lo que mostramos, dar una información de las especificidades de cada zona. 
Un ejemplo lo es este caso. Llevamos piezas como una cartera de veteranos, fotos de mambises de la zona de Jamal, de la Manga Histórica, lugar donde acampó el general Antonio Maceo en la guerra del 68, y una relación de veteranos que participaron en el Regimiento Maisí, en el que muchos jamalenses eran miembros. ¿Cuál fue la respuesta? Que la familia Urguellés nos trajera el libro de la subdelegación de los veteranos del Jamal y que otra familia, la Durán, nos trajera también para exhibir el estandarte que utilizó dicha subdelegación. Otras de las experiencias han sido realizadas con las escuelas. Una de ellas fue cuando nos dimos a la tarea de montar un museo móvil de flora y fauna de Baracoa. Para este, les planteamos a los estudiantes que integran el Grupo de apoyo de Flora y Fauna del Ipuec No. 30 qué pretendíamos. Les dimos la información bibliográfica; hablamos con la dirección del centro para que nos prestara un local y así pudimos montarlo. Ellos hicieron la colecta, clasificaron las especies, las disecaron, les pusieron pie de texto y se prepararon para dar a conocer la importancia de aquella a todos sus compañeros.

Otro montaje fue el realizado con otro grupo de estudiantes del grupo de Geografía. Era concerniente a los estolones geológicos. Ellos los buscaron; a través de un geólogo determinaron su tipología, zona de hallazgo y su importancia mineralógica. En esta ocasión no utilizamos las vitrinas porque eran muy pequeñas para el volumen de los objetos presentados. Nos valimos de mesas escolares que pusimos en el exterior de los laboratorios. Otro ejemplo fue el dedicado a la Polymita picta, molusco pulmonado, endémico de Baracoa y Maisí. Esta actividad se realizó con la escuela de Majayara, zona muy rica en este caracol. Los niños de la escuela rural trajeron ejemplares vivos y muertos. Los vivos se mostraron en algunos árboles alrededor del centro y los muertos se clasificaron por subescocías. Ejemplo: las nigrolimbatas, las roseolimbatas, etc. Nosotros apoyamos a los pioneros con un trabajo publicado acerca de este molusco en la revista El Yunque, órgano del Museo Matachín, el que le sirvió de información científica.

Por todo el trabajo comunitario de nuestra institución, a través de 20 años de labor ininterrumpida en las zonas de difícil acceso, el Consejo Nacional de Patrimonio y la Comisión Cubana de la Unesco nos dio el privilegio de ser sede del Primer Taller de Animación de los Museos en las Zonas Montañosas, que se realizó en la Escuela Primaria Primero de Abril de 1985, en la comunidad rural de Duaba, el 3 de mayo del 2002. Asistieron museólogos del Plan Turquino, que expusieron sus experiencias.

\section{Algunas valoraciones}

Considero que el museólogo desarrolla una labor ineludible y de altísima responsabilidad en el trabajo comunitario. El trabajo nuestro debe ser indivisible, por lo que hay que darle los mejores esfuerzos porque, cuanto más cohesionada 
sea esa conjunción de intereses de todos, mejor marcharán los objetivos propuestos. En nuestra labor hemos seguido esta línea de trabajo, que nos ha dado resultados positivos en el bregar del quehacer cultural.

Conocer de la formación educativo-cultural de los estudiantes de los distintos niveles de enseñanza, o de la visión de los pobladores de zonas apartadas y montañosas que no han tenido un constante acceso a la formación históricocultural, pese a las ventajas que en el campo de la educación, salud y en lo social han recibido de la Revolución, ha sido esencial para desplegar el trabajo en las diferentes comunidades. Sin este instrumento estamos desprovistos de implementos necesarios para emprender nuestras acciones culturales.

He meditado en muchas ocasiones en las cualidades que debe poseer un trabajador de nuestra institución. Esto ha sido análisis constante en estos años de labor cultural, en los que he contactado con disímiles personas dedicadas a cumplir lo orientado, estrictamente en muchos de los casos, y otros a hacer con amor.

Vivir en nuestra sociedad implica una cabal comprensión de los mecanismos que en ella se dan. Una valoración entre la importancia de la capacidad técnicointelectual y las cualidades innatas que debe caracterizarlo me ha llevado a la conclusión de que lo más importante es la identificación plena con la labor cultural que va a realizar y tener ese carisma que nos lleva a hacer con amor y a infiltrarse en el corazón de las comunidades.

El nivel educacional alcanzado en estos años, donde la población ha acumulado una fuerte instrucción, hace que el trabajador del museo debe tener una sólida preparación y conocer las últimas experiencias del país, dominar los acontecimientos culturales en el ámbito regional y universal, porque todo esto coadyuva a mirar con otra óptica y le permite aplicar lo adaptable, sin limitación y copia. Estas apreciaciones me han ayudado a tener una línea más certera para enfrentarme a las problemáticas que un museo presenta y a los objetivos que este tipo de institución se traza. Indudablemente, haberme pertrechado de estos conocimientos me ha permitido, con más habilidad, utilizar para sus distintas funciones los objetos museísticos, que son las fuentes primarias de nuestra institución.

El museólogo debe ser objetivo y racional; debe saber definir y enunciar claramente los objetivos y metas, proponiéndoselos reales, concretos, que se puedan cumplir viables y operativos. De igual forma, se hace imprescindible la determinación de los recursos disponibles con los que contamos; humanos, financieros y materiales.

Nosotros hemos tenido que sobrepasar escollos en lo relacionado con el financiamiento de nuestras actividades en estos años. No contar la institución con 
un presupuesto que pueda manejar y disponer, sin duda alguna ha constituido una limitación para el campo de posibilidades y de acción del centro... Aunque nunca paralizamos lo que nos habíamos trazado: si no había dietas para la transportación y alimentos, estos menesteres los hemos resuelto con el apoyo de las comunidades adonde llevábamos la actividad. En la medida que las posibilidades lo permitan, debe independizarse el presupuesto para cada institución; y esta deberá buscar los mecanismos que contribuyan a su financiamiento.

Medir sistemáticamente cómo marchan las tareas lo he aplicado con el concurso de todos los factores humanos que intervienen en la acción cultural, porque siempre los demás permiten intercambiar puntos de vista y perfeccionar el trabajo. Esto faculta evaluar la marcha del proyecto, los aciertos y desaciertos, inexactitudes e introducir cambios, cuando se hacen necesarios, porque la complejidad dialéctica nos afirma que siempre hay una constante movilidad y, a veces, lo previsto no es factible, aunque puntualizamos en estas discusiones el uso de posiciones lógicas y de raciocinio. Esto sirve para aclarar los conflictos que surjan, dándoles las mejores y más rápidas respuestas. De ahí hemos llegado a conclusiones más concretas que nos han servido para perfeccionar nuestra labor.

Estos años, en la contienda cultural, me han hecho llegar a las siguientes consideraciones:

Autovalorar lo mío, conocer qué tenía para decir de mi tierra y para enorgullecerme de ella, fueron elementos importantes para con avidez indagar en lo desconocido de Baracoa e iniciar el trabajo.

No es posible la consecución de una meta sin la perseverancia, el sistematismo $\mathrm{y}$, por encima de todo esto, el amor con el que se haga la obra propuesta.

Es esencial para un trabajo comunitario efectivo cumplir con las funciones del museo: inventariar, conservar e investigar. Sin estos instrumentos, la promoción es baldía.

Es imprescindible para nuestro trabajo la unión de todos los recursos institucionales y humanos, que hace realidad la cultura en el socialismo cubano. Es indudable que la participación de los factores humanos de cada comunidad en el trabajo cultural, cuando autorreconocen sus valores locales, se convierte en promotora de sus esencias y crece su sentido de pertenencia de manera inusitada.

La sistematización es una herramienta indispensable en el quehacer cultural de todos. No cumplir este aspecto es dilapidar el mejor esfuerzo del trabajo cultural.

Nuestros campesinos, nuestros pioneros de las zonas rurales, nuestros cooperativistas, a través de los museos móviles, han recibido el mensaje cultural, 
histórico, científico, lo que les ha permitido ampliar el universo de su cultura, que en las condiciones en las cuales viven no les es dable recibir como el hombre de la ciudad. Como respuesta recíproca hemos recibido informaciones históricas y nuestras colecciones se han nutrido de valiosas piezas. Indudablemente, a través del museo móvil, hemos despertado el amor por nuestras tradiciones históricas y hemos reforzado el sentido de pertenencia.

Siempre hemos seguido una línea de trabajo que nos ha dado resultados positivos: es no seguir las normas con esquemas, es no repetir con rigidez lo orientado y desglosarnos de los planes inflexibles o fijar metas invariables.

El museólogo siempre debe partir de la creación, porque la creatividad es saber dar respuestas a situaciones dadas y a los distintos problemas con los que se enfrenta. Él debe tener en cuenta que las experiencias no son adaptables a todas las circunstancias, porque todo es cambiable y vivimos en acelerado y dinámico movimiento.

Las discusiones constantes, el análisis sistemático de cómo abordar las actividades, de acuerdo con las peculiaridades de los asentamientos, unidos a la reflexión y a los debates sin prejuicios nos ha apoyado mucho en el trabajo diario.

Hay una cualidad importantísima que se debe poseer, y es la referida a su sensibilidad con su trabajo. Cuando él la posee, está apto para enfrentarse a las numerosas dificultades, a las incomprensiones, a los mecanismos burocráticos y financieros que frenan el cumplimiento de la acción cultural. La capacidad intelectual y el cúmulo de mayor cultura no son efectivos si no posee el carisma que lo lleva a hacer con amor y a infiltrarse en el corazón de la gente. Se debe ser optimista, alegre, afable: tener sentido del buen humor; debe caracterizarse por lo persuasivo y debe saber escuchar, convencer y poseer un tacto necesario para el trato con los pobladores.

Los postgrados, cursos, seminarios, las investigaciones y la participación en diferentes eventos han permitido a nuestros trabajadores ampliar su visión cultural y nos han abierto las posibilidades para la reflexión y el mejoramiento del trabajo. La planificación es un aparato indispensable porque esto le sirve para definir y enunciar claramente los objetivos y metas de manera clara y racional. Esto le permite más concreción, viabilidad y cumplimiento más operativos.

Soy de la opinión de que la evaluación es un termómetro que nos sirve para conocer los aciertos y desaciertos en los diseños previstos. Es un proceso permanente porque nos da la información precisa para continuar o reformular la concepción inicial. Otro punto es hacer uso sistemático de la divulgación porque ella coadyuva al desarrollo de cada actividad cultural que va encaminada a la elevación del nivel de vida de la población. 
La interrelación museo-comunidad es una vía efectiva para cumplir los objetivos que el museo como institución se traza. Esta relación biunívoca hace que los pobladores de los asentamientos se conviertan en una columna de sostén para algunas de las funciones del museo: el enriquecimiento de las colecciones, por una parte, y el flujo de la información para las investigaciones, por la otra. La premisa que hemos esgrimido como arma fundamental fue, es y será esta: que sin la comunidad el desarrollo de la cultura es imposible. 


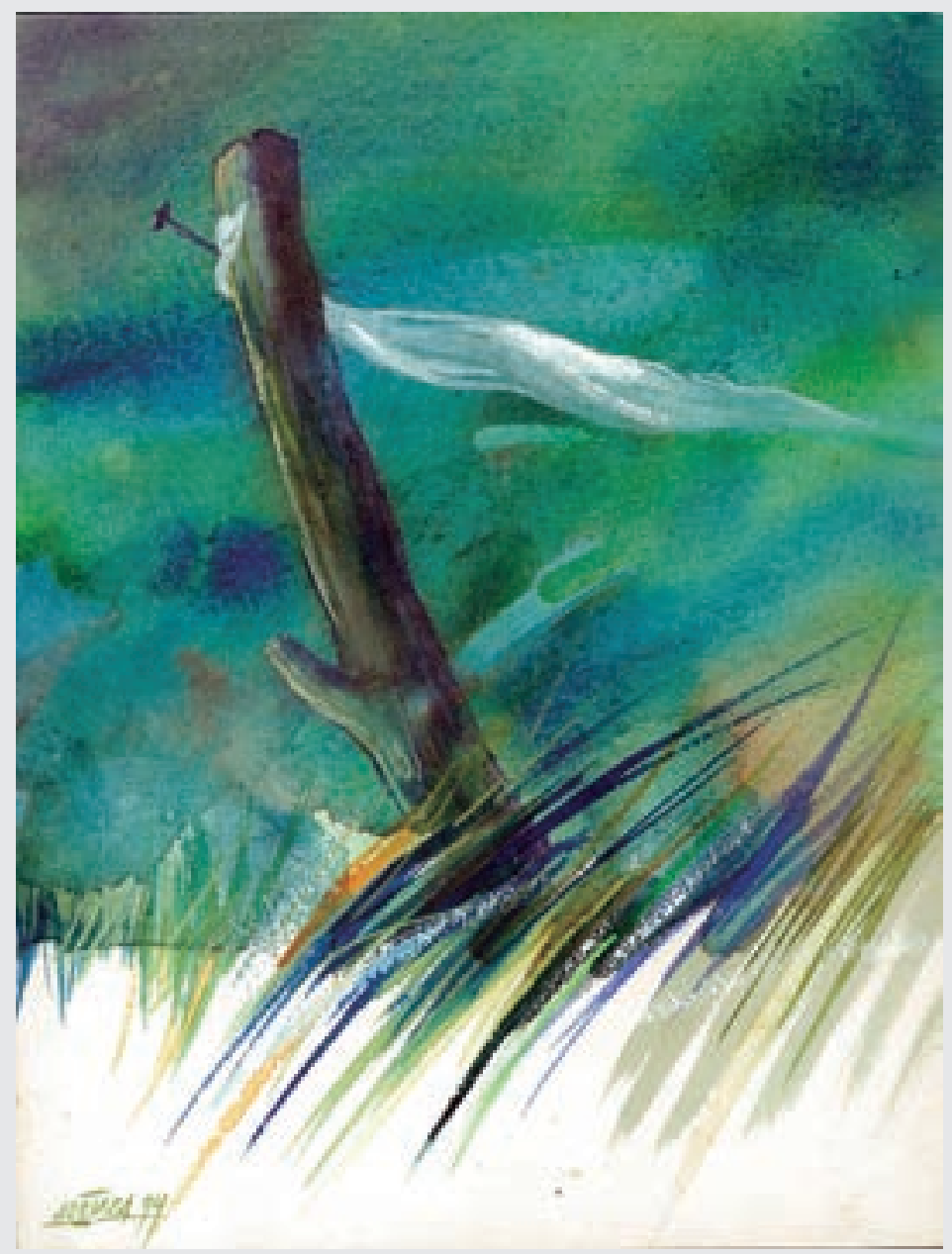

